ization of experimental research in particle physics, also apparent from the text:

With a pun of dubious taste, I could say that it is no longer sufficient to be a Rutherford, but one must be a RutherFord, meaning that the physicist must have at least some of the qualities of an industrialist and of a businessman [p.294].

Clearly, Segrè identifies "the physicist" here with the elite of the scientific community. He does not note that if some scientists are to be industrialists and businessmen, this implies that many other scientists and technicians must be workers and wage labourers. To carry his pun a step further, today there is a Reuther-Ford division among scientists (Walter Reuther was the head of the US Auto Workers trades' union).

The comments of a leading physicist such as Segrè on men and events, his views on the development of physics and its place in the scheme of things have an intrinsic interest. But the question naturally arises: how reliable is such an unashamedly personal account? I have the impression that, overall, it is a rather reliable source of information, but have only checked the chapter on Einstein with any care. Judgements of personality will naturally tend to differ. Against Segrè's view of Einstein:

He was not averse to playing the role of the great scientist; clearly, he enjoyed it. Perhaps this explains some of his affectations, his strange manner of dress, and some habits that may have been for show. After all, he was an admirer and friend of Charlie Chaplin [p.97],

one might want to set that of Leo Szilard, who was more closely associated with Einstein:

He is a man as free from vanity as I have ever seen. I have heard him talk to an audience of a thousand in German where he was at his best, and he talked to them as he would talk to a few friends gathered at his fireside... If you meet him you are struck with his great modesty and his great simplicity of heart [Leo Szilard: His Version of the Facts (MIT Press, 1978) p. 12].

As to biographical information, the chapter is fairly accurate, but I must report that there are several errors. For example, Einstein's academic career between 1908 and 1912 is incorrectly given on p.88, which also speaks of Einstein as disturbed by "the anti-Semitic atmosphere' in Prague at that time. The account of Einstein's theories is generally quite good, although Segrè gives more of an operationalist twist to Einstein's development of special relativity than I think is justified. More serious is the statement on p.95 that the experimental effects predicted by general relativity "are small and difficult to observe, so that even now there is no absolute and unequivocal confirmation of the general theory of relativity". While certainly true, it seems to imply that Segrè believes that some other theories have been absolutely and unequivocally confirmed. This and other statements (for example the first paragraph of p.292) make it clear that philosophical problems of physics are not Segrè's strong point.

No account of the development of nuclear physics can avoid some discussion of the development of nuclear weapons, and the impact of this development on the modern world as well as on the physics community itself. Segrè gives such an account, and makes a number of interesting comments on the personalities and roles of J. Robert Oppenheimer and Ernest O. Lawrence, for example. His stance is that of an enlightened member of the US scientific establishment; one cannot find any searching criticism of either the scientific or political establishments here. His account would have to be supplemented from other sources by anyone seeking a thorough understanding of the origins of our present nuclear predicament. I do not mean to imply by this that Segrè is not well aware of the problem. In the few pages he devotes to "the influence of science on the human condition", as he puts it, he states his views: science enhances human power. It also permits (at least approximately) anticipation of the consequences of certain courses of action. However, the process of decision at both the individual and the state level is dictated not by science but rather by obscure factors that I understand only dimly. They seem to me to be largely irrational, possibly dictated by behavioural forces, evolutionary drives, or subconscious demons. We thus see courses of action that to an outside observer appear totally irrational and destructive in their consequences. The armament race is an outstanding example. Because science enhances human power, it makes these foolish pursuits more and more dangerous, so much so that they may imperil the survival of the species ...

While the scientist has the specialized knowledge of his discipline, on other subjects he is pretty much prey to the same dark forces as is anybody else. His training and education may help him to overcome some of his irrational urges, but the idea that the objective, cool scientist is above the crowd is fallacious. This should be recognized by the scientists and by the public at large. Scientists are not priests of a magic religion [pp.288-289].

John Stachel is a Professor at Boston University, currently working at the Institute for Advanced Study, Princeton, New Jersey.

\title{
Nuclear technology for the layman
}

\section{Malcolm C. Scott}

Unlocking the Atom: A Hundred Years of Nuclear Energy. By Malcolm Longstaff. Pp. 175. (Frederick Muller: London, 1980.) £7.95.

THE story of the development of nuclear energy is striking, both for the intellectual excitement which it has generated as well as for the intense political and moral arguments which have surrounded its use for weapons and for peaceful purposes. Yet, paradoxically, there have been few books which have attempted to cover these developments, particularly the technical aspects, in a way which makes them accessible to the general reader.

Despite the disclaimer in the preface "... all I have been able to give is a sketchy account of some aspects, and particularly those which interest me most" - the scope of the book is broad. It starts with the discovery of uranium, radioactivity and fission and discusses the work leading to the two atomic bombs dropped on Japan. The post-War development of nuclear reactors for plutonium production is then covered, leading on to the start of the nonweapons orientated reactor programme. The main features of the principal power reactors in use around the world are outlined, followed by chapters on uranium and its fabrication into fuel (including the use of lasers for enrichment), fuel use and reprocessing, and radioactive waste disposal. There are then separate chapters on safety, on energy and the place of nuclear power, and on other uses of nuclear energy. Finally, in "Looking Ahead", the author touches on some of the current arguments relating to nuclear power (for example, the question of the blackmail value of plutonium and the possible role of thorium in separating the peaceful and non-peaceful uses) and outlines the principles of nuclear fusion. Throughout the book there are well-chosen photographs and numerous other figures.

The author keeps to his intention to give "little chemistry and no mathematics", yet, nevertheless, manages to provide a comprehensive technical coverage of the subject. In doing so he defines the terms which he uses in a non-technical way, so that the lay reader should not find it necessary to read with a technical dictionary at his elbow.

There are a few inconsistencies - for example, the abundance of uranium-235 is given variously as 1 part in 140,1 part in 139 and $0.3 \%$ ( 1 part in 333 : this is certainly a 
typographical error). Nevertheless, they are few, and the general tone of the text is one of technical correctness and authority. Yet, despite these undoubted virtues, there is something lacking: it is simply that the author has not succeeded in making the field as enthralling as he found it during his 24 years with the United Kingdom Atomic Energy Authority. Instead, one is left with the uneasy feeling that the book reads like a succession of the carefully worded, technically correct, but bland handouts favoured by public relations officers, particularly in the nuclear industry. The sense of excitement aroused by the initial discovery of fission is missing, as is any sense of the enormous technological achievement in harnessing nuclear power.
After all, the reason why nuclear power bears the brunt of the anti-technologists' onslaught is precisely because it is seen as the high technology, an almost unique amalgam of science and engineering. Yet none of this emerges. Everything is under control, doubts are smoothly assuaged and technology rules supreme.

Nevertheless, for the reader who is prepared to accept these limitations, the book provides an accessible and comprehensive survey of the nuclear scene at a level which invites a wide readership.

Malcolm C. Scott is Senior Lecturer in the Department of Physics, University of Birmingham, in charge of the MSc course on the physics and technology of nuclear reactors.

\section{Life as we know it: does anyone else?}

\section{Paul Davies}

\begin{abstract}
Life Beyond Earth: The Intelligent Earthling's Guide to Life in the Universe. By Gerald Feinberg and Robert Shapiro. Pp.480. (Morrow: 1980.) Hardback \$14.95; paperback \$7.95. Earth and Cosmos. By R. S. Kandel. Pp.270. (Pergamon: 1980.) Hardback \$30, £13.50; paperback $\$ 14.90, £ 6.95$.
\end{abstract}

Life Beyond Earth, proclaims the publisher's blurb, "is the result of a threeyear collaboration between a theoretical physicist and a biochemist ...". That sounds like a recipe for disaster, but the end product is remarkably coherent, if a little prolix. It is also somewhat pretentious, because it presents a range of ideas, varying from uncontentious standard biochemistry to the most outrageous and bizarre speculations, in a deceptively uniform and scholarly format.

It is, of course, the outrageous ideas that make this book such fun to read. The authors pin their colours firmly to the mast in Chapter 1: "We believe that most other attempts... have not been sufficiently imaginative in examining the possibilities for extraterrestrial life". To remedy this state of affairs, the reader is invited to consider the astonishing prospect of living creatures inhabiting the most unlikely of habitats - wallowing in the molten interior of the Earth, bobbing about inside the Sun, crawling over the surfaces of neutron stars, or floating serenely and nebulously in interstellar space. This is all good sci-fi stuff, but my main misgiving is that while the mere existence of a source of free energy and a mechanism for selforganization are certainly necessary conditions for the appearance of some form of life, can we really believe, as the authors assume, that they are sufficient?

A related problem to the happy prospect of a Universe teeming with exotic life forms is that it is far easier to believe in the evolution of intelligence, once life has actually gained a foothold, than in the initial appearance of living things. Yet if intelligence abounds in the cosmos, we would expect it to be conspicuous. Where is the alien technology, some of it presumably billions of years more advanced than ours? Unfortunately, Feinberg and Shapiro almost completely ignore the subjects of intelligence and alien communities, so do not attempt to face this central issue.

It would be misleading, however, to over-emphasize the bizarre in this book. The authors provide a valuable service in, for example, drawing attention to the distorted public image of the Viking experiments on Mars, popularly believed to have excluded the possibility of life there. In fact, as the authors' careful analysis shows, the results were ambiguous, and the experiments in any case left a lot to be desired in their underlying assumptions about Martian biology.

One can also be persuaded by their argument that the search for extraterrestrial life contributes hugely to the motivation for the general exploration of space. Public disappointment that space probes have not yet positively encountered even the tiniest form of life has contributed to the widespread disillusionment with these expensive enterprises. Yet the most likely abode for life in the Solar System Jupiter - has still to be closely explored.

Inevitably, for a book that tackles a subject for which no known subject matter yet exists, Life Beyond Earth contains liberal doses of philosophy. Specially singled out for attack are those whom the authors dub as "carbaquists" _. biochemical faint-hearts who believe that life based on the chemistry of carbon and water is the only possibility. As a physicist, the carbaquist viewpoint has always seemed to me chauvinistic; biochemists are doubtless more conservative.
Another delicate issue concerns the need for a clear definition of life. Superficial criteria such as the ability to reproduce, response to environment and so on are also displayed by systems that are normally regarded as inanimate, so Feinberg and Shapiro adopt a sort of global definition wherein life is manifested through the activity of a biosphere; that is, one should look to the highly organized and complex structure of interlocking organisms as an unambiguous indicator of life.

At the end of the day we are still left with the depressing fact that the discovery of extraterrestrial biospheres is unlikely to occur in the twentieth century, so all books of this sort really amount to little more than speculation, or at best educated guesses. Nevertheless, there is a real need for us to examine fresh perspectives of mankind and his place in the Universe. With that in mind, I found the book entertaining and generally informative.

In contrast to this ambitious work, Earth and Cosmos by Robert Kandel is more modest in aim though wider in scope. The author also provides a cosmic perspective of mankind by discussing in detail a whole range of physical processes that are relevant to the structure of the Earth and its immediate environment. This book is full of fascinating information, ranging from continental drift to the pollution of the atmosphere. There is an extensive discussion of both meteorology and climatology, and a detailed review of the Earth's motion. Earth and Cosmos makes good reading for non-specialists who want to know more about the planet we live on.

Paul Davies is Professor of Theoretical Physics at the University of Newcastle upon Tyne.

\section{Cosmic questions}

\section{Joseph Silk}

The State of the Universe. Edited by G.T. Bath. Pp. 199. (Oxford University Press: 1980.) £8.95, $\$ 24.95$.

DESPITE its obscure origin and intemperate past, the Universe has made a good recovery. Conditions have stabilized over the past several eons, and practically all observers now agree that a recession is with us for some time to come. However the long-term outlook remains controversial - some predict that the rate of inflation will eventually drop, heralding the onset of a long era of deflation; other forecasters, perhaps a majority, maintain that the inflation rate will hold steady into the remote future. A vocal minority even persist in finding evidence that the inflation rate is accelerating.

This situation must seem familiar to the student of economics. Likewise, cosmologists also have their differences. It 